\title{
OPEN Effect of salinity on the zinc(II) binding efficiency of siderophore functional groups and implications for salinity tolerance mechanisms in barley
}

\author{
George H. R. Northover ${ }^{1 凶}$, Yiru Mao ${ }^{1}$, Haris Ahmed ${ }^{1}$, Salvador Blasco ${ }^{2}$, Ramon Vilar ${ }^{3}$, \\ Enrique Garcia-España² \& Dominik J. Weiss ${ }^{1,4 凶}$
}

Bacteria, fungi and grasses use siderophores to access micronutrients. Hence, the metal binding efficiency of siderophores is directly related to ecosystem productivity. Salinization of natural solutions, linked to climate change induced sea level rise and changing precipitation patterns, is a serious ecological threat. In this study, we investigate the impact of salinization on the zinc(II) binding efficiency of the major siderophore functional groups, namely the catecholate (for bacterial siderophores), $\alpha$-hydroxycarboxylate (for plant siderophores; phytosiderophores) and hydroxamate (for fungal siderophores) bidentate motifs. Our analysis suggests that the order of increasing susceptibility of siderophore classes to salinity in terms of their zinc(II) chelating ability is: hydroxamate $<$ catecholate $<\alpha$-hydroxycarboxylate. Based on this ordering, we predict that plant productivity is more sensitive to salinization than either bacterial or fungal productivity. Finally, we show that previously observed increases in phytosiderophore release by barley plants grown under salt stress in a medium without initial micronutrient deficiencies, are in line with the reduced zinc(II) binding efficiency of the $\alpha$-hydroxycarboxylate ligand and hence important for the salinity tolerance of whole-plant zinc(II) status.

Organic ligands play a critical role in the cycling of trace metals. Through complexation processes, they control the mobility of contaminants and regulate the bioavailability of micronutrients ${ }^{1-3}$. One group of organic ligands found ubiquitously in natural solutions are siderophores ${ }^{4}$. Siderophores have a high affinity for iron(III) and are secreted by bacteria, fungi and grasses. Siderophores are typically hexadentate in nature, forming octahedral complexes with metal ions ${ }^{5}$. The three major building-blocks of siderophores are the catecholate, $a$-hydroxycarboxylate and hydroxamate bidentate motifs (Fig. 1a-c) ${ }^{6}$. Whereas the majority of bacterial siderophores contain only catecholate ligands, plant-produced siderophores (phytosiderophores) contain a mixture of functional groups, including $\alpha$-aminocarboxylates and $\alpha$-hydroxycarboxylate units. Hydroxamic siderophores tend to be synthesized by fungi. Model ligands featuring their functional groups are widely studied in place of real siderophores ${ }^{7}$. Whilst functional groups do not account for structural effects, they do capture the donor properties of siderophores, which in turn provide a significant amount of stability to metal-siderophore complexes ${ }^{8}$. Despite their high affinity for iron(III), siderophores are involved in the cycling of other metals ${ }^{9,10}$. In both bacteria and grasses, siderophores are known to function as zincophores ${ }^{11-13}$. For example, barley plants subjected to zinc-deficiency absorb more than $50 \%$ of their zinc(II) from soils as zinc(II)-phytosiderophore complexes ${ }^{14}$.

Salinization of groundwater and soil solutions is a serious, and increasingly concerning, ecological threat linked to climate change. Salinization of natural solutions is driven by sea level rise, storm surges, changes to hydrological cycles (low precipitation, high surface evaporation), weathering of native rocks and irrigation with saline water ${ }^{15,16}$. Freshening-up events in brackish solutions are becoming more intense in response to changing

${ }^{1}$ Department of Earth Science and Engineering, Imperial College London, South Kensington Campus, London SW7 2AZ, UK. ${ }^{2}$ Instituto de Ciencia Molecular (ICMol), University of Valencia, C/Catedrático José Beltrán Martínez, 2, 46980 Paterna, Valencia, Spain. ${ }^{3}$ Department of Chemistry, Imperial College London, White City Campus, London W12 0BZ, UK. 'Department of Civil and Environmental Engineering, Princeton University, Princeton, NJ 08540, USA. ${ }^{\varpi}$ email: george.northover16@imperial.ac.uk; d.weiss@imperial.ac.uk 
(a)<smiles>[O-]c1ccccc1[O-]</smiles>

Catecholate $(9.1 ; 13.0)$

(b)

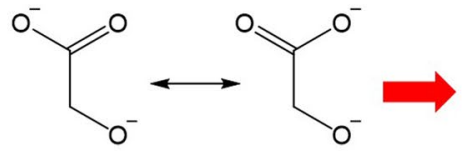

$\alpha$-hydroxycarboxylate $(3.0 ; 14.5)$

(c)

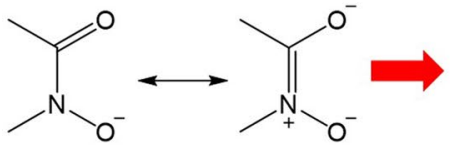

Hydroxamate (9.0) (d)

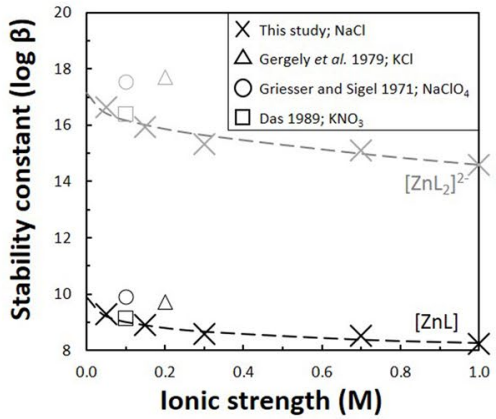

(e)

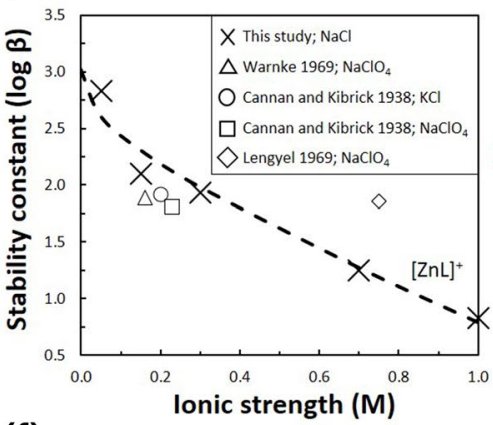

(f)

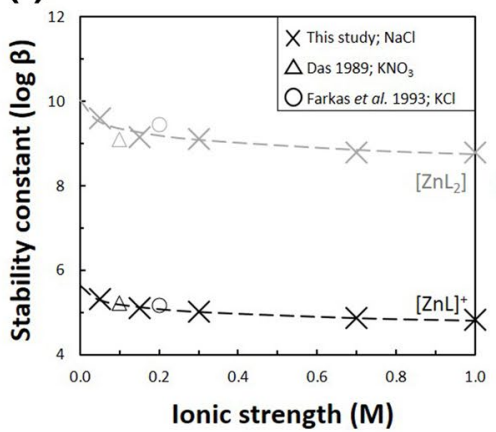

(g)

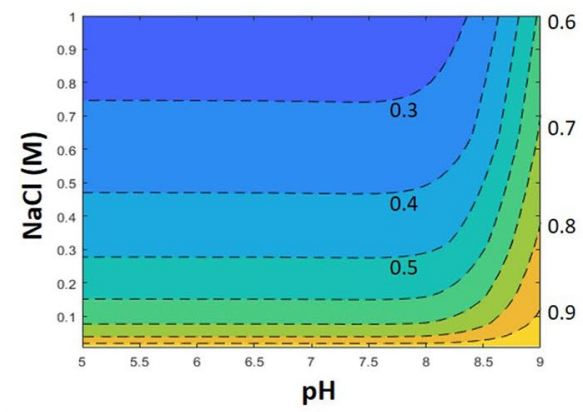

(h)

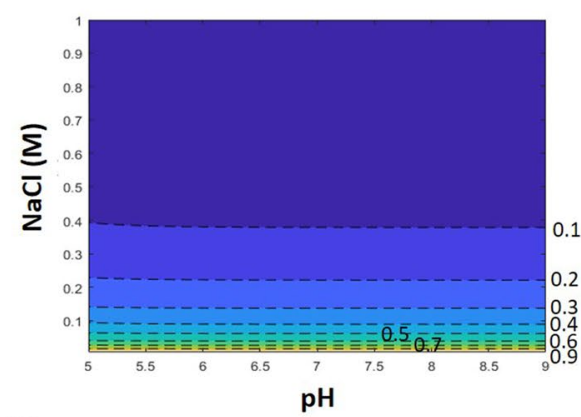

(i)

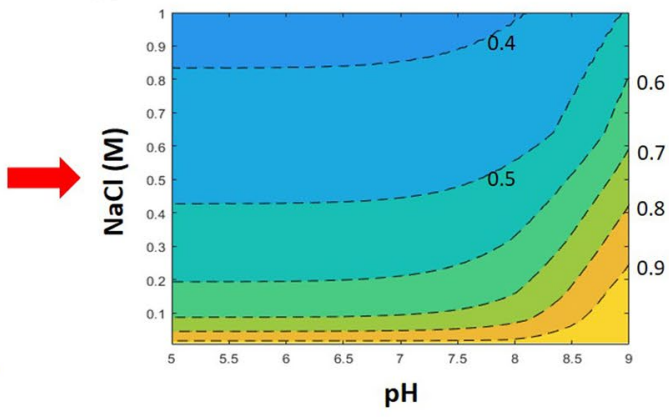

Figure 1. (a-c) Three major bidentate components of siderophores (approximate $\mathrm{pK}_{\mathrm{a}}$ values). (df) Experimental zinc(II)-ligand stability constants for (d) pyrocatecholate, (e) glycolic acid, and (f) acetohydroxamic acid in $\mathrm{NaCl}$ at $T=298.1 \mathrm{~K}$. For each species, the modified Extended Debye-Hückel model has been parameterised using experimental data from this study and is shown as a dashed line. Literature data at $T=298.1 \mathrm{~K}$ is included in the figure for comparison ${ }^{50-58}$. Complete set of analytical results for the zinc(II)/ ligand systems, including stability constants for hydrolysed zinc(II)-ligand species, reported in Table S1. (g-i) Zinc(II) binding efficiency contour plots for (g) pyrocatecholate, (h) glycolic acid, and (i) acetohydroxamic acid. A zinc(II) binding efficiency value is calculated for any given $\mathrm{pH} /$ salinity condition by normalizing the fraction of zinc(II) complexed under these conditions, by the fraction of zinc(II) complexed by the ligand in a reference freshwater solution at the same $\mathrm{pH}$. The $\mathrm{NaCl}$ concentration of the reference solution is equivalent to the salinity of fresh groundwater $([\mathrm{NaCl}]=0.005 \mathrm{M})$. Tabulated raw data is supplied in Tables S5-S7.

precipitation patterns ${ }^{17,18}$. In laboratory investigations, salinity is often represented by the concentration of $\mathrm{NaCl}$ $([\mathrm{NaCl}])^{19,20}$. The effect of increased salinity on the complexation of zinc(II) by humic and low-molecular-weight organic acids has been studied ${ }^{21-23}$. For example, a sharp decrease in the proportion of zinc(II) bound to humic acid has been observed when small amounts of $\mathrm{NaCl}$ were added to river water (equivalent to $0.05 \mathrm{M} \mathrm{NaCl})^{22}$. Humic acid has various functional groups with carboxylates and phenolates dominating its surface charge and reactivity ${ }^{24}$. Our prediction is that the ability of siderophores to bind with zinc(II) will be hindered by salinization. This is because the increased concentration of salt ions will decrease the stability of zinc(II)-siderophore complexes through: (i) activity effects and (ii) competition with chloride ions for zinc(II). If siderophores are less efficient at scavenging zinc(II) and other micronutrients, this will have fundamental implications for ecosystem productivity.

The strength of a metal-ligand complex is characterised by a stability constant. Stability constants calculated at standard state are known as intrinsic stability constants $\left(\log \beta^{0}\right)$. Experimentally measured stability constants are conditional $(\log \beta)$ and their value depends on the conditions under which they were measured (ionic strength, temperature and pressure $)^{23,25}$. A conditional stability constant can be adjusted for ionic strength indirectly by 
calculating activity coefficients. However, indirect approaches often require ion-specific parameters to be known and have theoretical limitations which lead to a systematic bias in the adjustment of stability constants ${ }^{11,26}$. A more accurate, direct, method for studying the ionic strength dependence of stability constants involves measuring stability constants at a limited number of points within an ionic strength range of interest and then fitting a modified version of the Extended Debye-Hückel equation (Eq. 1) or specific ion interaction theory to the experimental data series ${ }^{27-29}$. We previously used a direct approach to develop an accurate description of the ionic strength dependence of stability constants for zinc(II)-citrate and zinc(II)-desferrioxamine B (DFOB) complexes $^{30}$.

$$
\log \beta^{0}=\log \beta-0.51 z^{*} \frac{\sqrt{ } \mathrm{I}}{1+1.5 \sqrt{ } \mathrm{I}}+f(I)
$$

where $\mathrm{z}$ is the charge of the ion, $\mathrm{z}^{*}=\sum\left(\mathrm{z}_{\text {reactants }}^{2}\right)-\sum\left(\mathrm{z}_{\text {products }}^{2}\right)$, I is ionic strength $(\mathrm{M})$ and $f(I)$ is a linear function of ionic strength that can be formulated in different ways. The simplest expression for this term is $f(I)=C I$, where $C$ is the only adjustable parameter. Usually, this simple choice is sufficient to explain the experimental data trend in a wide ionic strength range, generally $<1.0 \mathrm{M}$.

With an accurate description of the ionic strength dependence of stability constants for zinc(II)-siderophore functional group complexes, it is possible to parameterize a two-component model (zinc(II) and ligand) for each functional group at any ionic strength, including at $0.005 \mathrm{M}$, the ionic strength representative for freshwater solutions ${ }^{31,32}$. A zinc(II) binding efficiency value can then be calculated for any given $\mathrm{pH} /$ salinity condition by normalizing the fraction of zinc(II) complexed under these conditions, by the fraction of zinc(II) complexed by the ligand in a reference freshwater solution at the same $\mathrm{pH}$ (Eq. 2). By comparing zinc(II) binding efficiency contour plots for siderophore functional groups over an environmentally relevant $\mathrm{pH} v s$. salinity study region, the relative susceptibility of different siderophore classes to salinization can be established in terms of their zinc(II) chelating ability. There are few studies on the influence of ionic strength on hydrophobic interactions ${ }^{33-36}$. However, it has been proposed that the binding affinity of hydrophobic ligands is less affected by variations in ionic strength ${ }^{37}$.

$$
\mathrm{BE}_{x, y}=\frac{\left(\frac{\mathrm{ZnL}}{\mathrm{Zn}}\right)_{x, y}}{\left(\frac{\mathrm{ZnL}}{\mathrm{Zn}}\right)_{x, z}}
$$

where $\mathrm{BE}_{x, y}$ is binding efficiency at $\mathrm{pH}=x$ and ionic strength $=y,\left(\frac{\mathrm{ZnL}}{\mathrm{Zn}}\right)_{x, y}$ is the fraction of $\mathrm{zinc}$ (II) complexed by the siderophore functional group at $\mathrm{pH}=x$ and ionic strength $=y$ and $\left(\frac{\mathrm{ZnL}}{\mathrm{Zn}}\right)_{x, z}$ is the fraction of $\mathrm{zinc}$ (II) complexed by the siderophore functional group at $\mathrm{pH}=x$ and a reference ionic strength $=z$. The reference ionic strength used is equivalent to the salinity of fresh groundwater $(0.005 \mathrm{M})$.

Various barley genotypes have demonstrated an ability to maintain whole-plant zinc(II) content under $\mathrm{NaCl}$ stress when grown in a soil or hydroponic solution without initial micronutrient deficiencies i.e., no micronutrient limitations prior to salinization (Fig. S1; Table S1) ${ }^{38,39}$. Moreover, hydroponic investigations where wild (Hordeum maritimum) and cultivated (H. vulgare) barley genotypes were grown in aqueous solutions without initial micronutrient deficiencies have observed that phytosiderophore release increases after a $0.10-0.20 \mathrm{M}$ $\mathrm{NaCl}$ salinization of the growth medium ${ }^{40}$. One explanation for an increase in phytosiderophore release by grasses under salt stress is that it is a response to secondary micronutrient limitations induced by the disruption of uptake pathways ${ }^{40}$. This explanation leads to the hypothesis that previously observed increases in phytosiderophore release by barley plants grown under salt stress in a medium without initial micronutrient deficiencies, are important for the salinity tolerance of whole-plant zinc(II) status. The effectiveness of phytosiderophores at scavenging zinc(II) is linked to the stability of zinc(II)-phytosiderophore complexes. Hence, the zinc(II) binding efficiency plot for the functional group relevant for phytosiderophores can be used to estimate the increase in phytosiderophore concentration required at different salinities to maintain the overall amount of zinc(II) complexed by phytosiderophores.

The aim of this study is to quantify the effect of salinity on the zinc(II) binding efficiency of siderophore functional groups. Following this, to assess the implications for salinity tolerance mechanisms in barley.

(i) For the first time, we develop an accurate description of the ionic strength dependence of zinc(II) stability constants with catecholate (pyrocatecholate; PYR), $a$-hydroxycarboxylate (glycolic acid; GLY) and hydroxamate (acetohydroxamic acid; AHA) functional groups in $\mathrm{NaCl}$. We do this experimentally by determining the zinc(II) stability constants with each functional group at five $[\mathrm{NaCl}](0.05,0.15,0.30$, 0.70 , and $1.00 \mathrm{M}$ ) before using this data to parameterize a modified version of the Extended DebyeHückel equation for each ligand. We test the validity of using a functional group as a representative of a real siderophore by comparing the ionic strength dependence model for zinc(II) stability constants with the hydroxamate functional group, with the ionic strength dependence model for zinc(II) stability constants with a real hydroxamate siderophore (DFOB) studied previously ${ }^{30}$. We highlight the benefits of the direct approach for studying the ionic strength dependence of stability constants.

(ii) Secondly, we employ the ionic strength dependence models to produce zinc(II) binding efficiency contour plots for each of the functional groups between $\mathrm{pH} 5-9$ and $0.01-1.00 \mathrm{M} \mathrm{NaCl}$. This allows us to predict which type of siderophore is most susceptible to the effects of salinity in terms of their zinc(II) chelating 
ability. We examine whether the susceptibility of the different classes of siderophore correlates with the hydrophobicity of the representative ligands.

(iii) Finally, we test the hypothesis that previously observed increases in phytosiderophore release by barley plants grown under salt stress in a medium without initial micronutrient deficiencies, are important for the salinity tolerance of whole-plant zinc(II) status. To achieve this objective, we use the zinc(II) binding efficiency contour plot for GLY (phytosiderophores contain carboxylate functional groups).

\section{Methodology and experimental set-up}

Determination of stability constants. Chemicals. Zinc(II) solutions were prepared by dissolving the corresponding mass of $\mathrm{ZnCl}_{2}$ (99\%, anhydrous, VWR) in water; the exact concentration was determined by complexometric titration against ethylenediaminetetraacetic acid (EDTA) standard solutions (Fisher Scientific). Standard $\mathrm{HCl}$ solutions were prepared from concentrated $\mathrm{HCl}$ (Sigma-Aldrich-Honeywell) and standardized with tris(hydroxymethyl)aminomethane (TRIS) (Roche Diagnostics). $\mathrm{CO}_{2}$-free $\mathrm{NaOH}$ standard solutions were supplied by Fisher Scientific and were preserved from atmospheric $\mathrm{CO}_{2}$ by means of soda lime traps. Electrolyte solutions of $\mathrm{NaCl}$ were prepared from the pure salt (VWR). PYR, GLY and AHA salts (Sigma-Aldrich) were used to prepare catecholate, $\alpha$-hydroxycarboxylate and hydroxamate ligand solutions, respectively. Purified water $\left(R=15 \mathrm{M} \Omega \mathrm{cm}^{-1}\right)$, grade A glassware and analytical grade reagents were used throughout.

Potentiometric titrations. Potentiometric measurements were carried out at $T=298.1 \pm 0.1 \mathrm{~K}$ in thermostatted cells. The setup consisted of a Metrohm model 888 Titrando apparatus controlled by Metrohm TiAMO 1.2 software equipped with a combined gel electrode (VWR model 662 1759). Estimated precision was $0.2 \mathrm{mV}$ and $0.003 \mathrm{ml}$ for the electromotive force and titrant volume readings, respectively. All the potentiometric titrations were carried out under magnetic stirring and bubbling purified presaturated $\mathrm{N}_{2}$ through the solution to exclude $\mathrm{O}_{2}$ and $\mathrm{CO}_{2}$.

Before studying the zinc(II)/ligand systems, the protonation constants $\left(\mathrm{pK}_{\mathrm{a}}\right)$ of the corresponding ligand were determined at different ionic strengths $(0.05 \leq \mathrm{M} \leq 1.00)$ in $\mathrm{NaCl}$ solutions. A $30 \mathrm{ml}$ solution containing each ligand $([\mathrm{L}]=5-10 \mathrm{mM}), \mathrm{NaCl}$ and $\mathrm{HCl}$ was titrated with standard $\mathrm{NaOH}$ solutions. For the zinc(II)/ligand systems, the titrant solutions consisted of different amounts of ligand $([\mathrm{L}]=5-10 \mathrm{mM})$, zinc(II) $([\mathrm{Zn}]=0.5-5 \mathrm{mM})$ and a suitable amount of $\mathrm{HCl}$ and $\mathrm{NaCl}$. All the measurements were carried out with an excess of the ligand, with respect to zinc(II) and at different zinc(II):ligand molar ratios. The selection of ratios investigated was determined by simulating titrations using Hyperquad Simulation and Speciation computer software (HySS $)^{41}$. $[\mathrm{Zn}]$ and $[\mathrm{L}]$ were negligible compared to the background electrolyte concentrations. Calculations showed that ionic strength remained within $10 \%$ of the targeted value throughout all titrations. To account for the influence of zinc(II) hydrolysis in the zinc(II)/ligand systems, zinc(II) titrations were carried out separately at each ionic strength to determine the hydroxide constants so that these constants could be included in the equilibrium model used to refine the titration data. In these titrations, the zinc(II) concentration in the analyte solution was $0.7 \mathrm{mM}$.

Before each experiment, independent titrations of strong acid solutions with standard base were carried out under the same medium and ionic strength conditions as the systems to be investigated, with the aim of determining the electrode potential $\left(\mathrm{E}^{0^{3}}\right)$ using GLEE software ${ }^{42}$. In this way, the $\mathrm{pH}$ scale used was the total scale, $\mathrm{pH}=-\log [\mathrm{H}]^{+}$, where $[\mathrm{H}]^{+}$is the free proton concentration. For each titration, approximately 80 to 100 data points were collected. The equilibrium state during titrations was checked by confirming the time required to reach equilibrium.

Calculating stability constants from titration data. The software program Hyperquad was used to determine the equilibrium model and to calculate $\mathrm{pK}_{\mathrm{a}}$ and stability constants from the potentiometric data set ${ }^{43}$. For each set of $\mathrm{pK}_{\mathrm{a}}$ constants or zinc(II):ligand ratio studied, at least two repeat titrations were performed. The titration curves for each system were treated as a single set when refining the stability constants. This meant that the refinement procedure was run on both curves at the same time to derive a single set of constants. The error reported on the stability constants is the standard deviation given in the Hyperquad output file. Examples of Hyperquad files for the zinc(II)/PYR system are provided on the Zenodo repository (https://doi.org/10.5281/zenodo.4641710).

Ionic strength dependence of stability constants. The ionic strength dependence of the stability constants was studied with the modified version of the Extended Debye-Hückel equation ${ }^{28}$. The Monte Carlo method, as described by $\mathrm{Hu}$ et al. ${ }^{43}$, was used to estimate $95 \%$ confidence intervals on the parameters of ionic strength dependence; for each species, predicted stability constants were resampled using an inverse of the cumulative normal distribution function to give sets of simulated data from which the unknown parameters were optimized ${ }^{44}$. An example Excel calculation file for the application of the modified version of the Extended Debye-Hückel equation to the zinc(II)/PYR system (including the calculation of error on parameters of ionic strength dependence) has been uploaded to the Zenodo repository (https://doi.org/10.5281/zenodo.4641710).

To quantify the improvement of using a direct $v s$. indirect method for studying ionic strength dependence, the Davies equation (Eq. 3) was applied to the $\mathrm{zinc}(\mathrm{II}) / \mathrm{PYR}$ data. Speciation calculations for a $[\mathrm{Zn}]=10^{-6} \mathrm{M}$ and $[\mathrm{L}]=10^{-5} \mathrm{M}$ system at infinite dilution were conducted with the aid of HySS. The [Zn] and [L] conditions adopted here, and in the next section, are the concentrations typically used when studying the effectiveness of ligands ${ }^{45,45}$. The error on each speciation calculations was determined by re-running the analysis with the high/ low estimates for the calculated intrinsic stability constants that can be derived from experimental data. The error was negligible and so is not shown in the associated plots. 


\begin{tabular}{|l|l|l|l|l|l|l|l|l|}
\hline Ligand & Equilibrium & $\mathbf{0 . 0 5}$ & $\mathbf{0 . 1 5}$ & $\mathbf{0 . 3 0}$ & $\mathbf{0 . 7 0}$ & $\mathbf{1 . 0 0}$ & $\mathbf{l o g} \boldsymbol{\beta}^{\mathbf{0}}$ & $\boldsymbol{C}^{\mathbf{b}}$ \\
\hline \multirow{2}{*}{ PYR } & $\mathrm{H}^{+}+\mathrm{L}^{2-}=\mathrm{HL}^{-}$ & $12.16 \pm 0.03$ & $11.97 \pm 0.01$ & $11.94 \pm .01$ & $11.96 \pm 0.01$ & $11.79 \pm 0.01$ & $12.489 \pm 0.009$ & $0.183 \pm 0.015$ \\
\cline { 2 - 9 } & $2 \mathrm{H}^{+}+\mathrm{L}^{2-}=\mathrm{H}_{2} \mathrm{~L}$ & $21.36 \pm 0.07$ & $21.14 \pm 0.02$ & $21.06 \pm 0.02$ & $21.04 \pm 0.02$ & $20.88 \pm 0.02$ & $21.874 \pm 0.001$ & $0.296 \pm 0.001$ \\
\hline GLY & $\mathrm{H}^{+}+\mathrm{L}^{-}=\mathrm{HL}$ & $3.55 \pm 0.01$ & $3.49 \pm 0.01$ & $3.54 \pm 0.01$ & $3.44 \pm 0.01$ & $3.39 \pm 0.01$ & $3.750^{\mathrm{b}}$ & $0.070^{\mathrm{b}}$ \\
\hline \multirow{2}{*}{$\mathrm{AHA}$} & $\mathrm{H}^{+}+\mathrm{L}^{-}=\mathrm{HL}$ & $9.28 \pm 0.01$ & $9.06 \pm 0.01$ & $9.10 \pm 0.01$ & $9.04 \pm 0.01$ & $9.07 \pm 0.01$ & $9.376 \pm 0.001$ & $0.085 \pm 0.001$ \\
\hline \multirow{4}{*}{ DFOB $^{\mathrm{a}}$} & $\mathrm{H}^{+}+\mathrm{L}^{3-}=\mathrm{HL}^{2-}$ & $11.07 \pm 0.07$ & $10.74 \pm 0.04$ & $10.36 \pm .02$ & $10.35 \pm 0.02$ & $10.14 \pm 0.06$ & $11.491 \pm 0.003$ & $-0.169 \pm 0.003$ \\
\cline { 2 - 9 } & $2 \mathrm{H}^{+}+\mathrm{L}^{3-}=\mathrm{H}_{2} \mathrm{~L}^{-}$ & $20.94 \pm 0.09$ & $20.25 \pm 0.06$ & $19.84 \pm 0.04$ & $19.77 \pm 0.04$ & $19.77 \pm 0.08$ & $21.530 \pm 0.006$ & $0.173 \pm 0.011$ \\
\cline { 2 - 9 } & $3 \mathrm{H}^{+}+\mathrm{L}^{3-}=\mathrm{H}_{3} \mathrm{~L}$ & $30.05 \pm 0.12$ & $29.10 \pm 0.09$ & $28.61 \pm 0.07$ & $28.60 \pm 0.08$ & $28.57 \pm 0.12$ & $30.691 \pm 0.012$ & $0.194 \pm 0.012$ \\
\cline { 2 - 8 } & $4 \mathrm{H}^{+}+\mathrm{L}^{3-}=\mathrm{H}_{4} \mathrm{~L}^{+}$ & $38.83 \pm 0.14$ & $37.46 \pm 0.13$ & $37.00 \pm 0.10$ & $36.97 \pm 0.16$ & $36.92 \pm 0.14$ & $39.250 \pm 0.023$ & $-0.079 \pm 0.043$ \\
\hline
\end{tabular}

Table 1. Ligand protonation constants $(\log \beta)$ at different $[\mathrm{NaCl}](\mathrm{M})$ and $T=298.1 \mathrm{~K} .{ }^{\mathrm{a}} 30 .{ }^{\mathrm{b}}$ Error $<0.001$ and therefore not reported.

$$
-\log \gamma_{i}=-\mathrm{Az}_{i}^{2}\left\{\frac{\sqrt{ } \mathrm{I}}{1+\sqrt{ } \mathrm{I}}-0.3 \mathrm{I}\right\}
$$

where $\mathrm{A}$ is a dielectric constant of the solvent, $\mathrm{z}$ is the charge of the ion and $\mathrm{I}$ is ionic strength (M).

Construction of zinc(II) binding efficiency contour plots. For each functional group, HySS was used to model a $[\mathrm{Zn}]=10^{-6} \mathrm{M}$ and $[\mathrm{L}]=10^{-5} \mathrm{M}$ system at 9 ionic strengths $(0.005,0.01,0.02,0.04,0.08,0.16,0.32$, 0.64 , and $1.28 \mathrm{M} \mathrm{NaCl}$ ). The ionic strength conditions sampled were deliberately weighted towards the lower ionic strength values, where we expect that binding efficiency is most variable. The stability constants used in the HySS models were determined by employing the ionic strength dependence models derived in the preceding phase of the investigation. The tabulated data was extracted into Excel and binding efficiencies were calculated between $\mathrm{pH}$ 5-9 by solving Eq. (2). This $\mathrm{pH}$ range was chosen because it covers the diverse conditions encountered in natural solutions ${ }^{46-48}$. The dataset was then imported into MATLAB and a scattered interpolation was performed to create a meshgrid which could be plotted as a 2D contoured surface map (Note S1). The use of these interpolation methods to generate a spatially continuous dataset is widespread in the environmental sciences ${ }^{49}$. The error on the parameters of ionic strength dependence had no effect on speciation, and thus did not influence the zinc(II) binding efficiency calculations.

Calculation of the increase in phytosiderophore concentration required at different salinities to maintain the overall amount of zinc(II) complexed by phytosiderophores. In this section we use the zinc(II) binding efficiency contour plot for GLY. This is because phytosiderophores contain carboxylate functional groups. The zinc(II) binding efficiency of GLY was determined at 10 equally spaced intervals between 0.01 and $0.30 \mathrm{M} \mathrm{NaCl}$ at $\mathrm{pH} 5$ and $\mathrm{pH} 8$, respectively. The two $\mathrm{pH}$ values selected represented end-member conditions i.e., the minimum/maximum $\mathrm{pH}$ that might be expected in real soil solutions ${ }^{46-48}$. For each $\mathrm{pH} / \mathrm{NaCl}$ point, Eq. (4) was then used to calculate the theoretical increase in phytosiderophore concentration required at that $\mathrm{pH} / \mathrm{NaCl}$ condition for the molar fraction of zinc(II) complexed by phytosiderophores to remain the same as in a freshwater solution at the same $\mathrm{pH}$. For example, if the zinc(II) binding efficiency at the sample $\mathrm{pH} / \mathrm{NaCl}$ point was 0.5 , then the phytosiderophore concentration has to double to maintain the overall amount of complexed zinc(II) i.e., $\mathrm{R}_{x, y}=2$.

$$
\mathrm{R}_{x, y}=\left(\frac{1}{\mathrm{BE}_{x, y}}\right)
$$

where $\mathrm{BE}_{x}, y$ is the binding efficiency at $\mathrm{pH}=x$ and ionic strength $=y$ and $\mathrm{R}_{x, y}$ is the relative increase in concentration of the ligand required at $\mathrm{pH}=x$ and ionic strength $=y$ for the molar fraction of zinc(II) complexed by the ligand to be equal to the molar fraction of zinc(II) complexed by the ligand at the same $\mathrm{pH}$ in a freshwater solution.

\section{Results and discussion}

Accurate description of the ionic strength dependence of stability constants for siderophore functional groups. Values of protonation constants for PYR, GLY and AHA (this study), and DFOB ${ }^{30}$, are reported at different $[\mathrm{NaCl}]$ and $T=298.1 \mathrm{~K}$ in Table 1 with the parameters of ionic strength dependence. Experimental and modelled zinc(II)-ligand stability constants are presented in Fig. 1d-f with literature data reported at $T=298.1 \mathrm{~K}$ in electrolyte solutions between 0.00 and $1.00 \mathrm{M}$ ionic strength. Complete set of analytical results for the zinc(II)/ligand systems, including stability constants for hydrolysed zinc(II)-ligand species, reported in Table S2. Stability constants for hydrolysed zinc(II) species are reported in Table S3. The errors reported on the measured protonation/stability constants and $\log \beta^{0}$ do not have an effect on subsequent speciation calculations. The errors reported on $C$ are up to an order of magnitude larger than in similar studies ${ }^{29}$. However, a sensitivity analysis on the three zinc(II)-ligand species with the largest relative error on $C$, shows that where $\log \beta^{0}$ is recalculated for the maximum/minimum possible $C$ values, $\log \beta^{0}$ remains within its error range. Hence, the error on 
$C$ does not affect the accuracy of $\log \beta^{0}$. The error envelope for the modified Extended Debye-Hückel models in Fig. 1d-f, calculated using the uncertainty on the parameters of ionic strength dependence, was too narrow to display on the plot (less than the width of the line representing the models).

Zinc(II)-ligand stability constants measured in this study are in good agreement with those measured in previous studies at similar ionic strengths ${ }^{50-58}$. For example, the 1:1 zinc(II)-GLY stability constant we report at $0.15 \mathrm{M} \mathrm{NaCl}$ differs by $<0.25 \log$ units from the $1: 1 \mathrm{zinc}(\mathrm{II})$-GLY stability constant reported in $0.1 \mathrm{M} \mathrm{KNO}_{3}$ and $0.2 \mathrm{M} \mathrm{KCl}$. In agreement with previous investigations, the equilibrium model with the best statistical fit to the PYR potentiometric data comprises two zinc(II)-PYR species ([ZnL] and $\left.\left[\mathrm{ZnL}_{2}\right]^{2-}\right)$ and the equilibrium model with the best statistical fit to the GLY potentiometric data comprises just one zinc(II)-GLY species $\left([\mathrm{ZnL}]^{+}\right)^{50,59,60}$. The stability of the GLY structure is approximately $7 \log \beta$ units lower than the equivalent 1:1 zinc(II)-PYR structure. For the zinc(II)/AHA system, the equilibrium model with the best statistical fit to the data and makes the most chemical sense includes four zinc(II)-AHA species; $[\mathrm{ZnL}]^{+},\left[\mathrm{ZnL}_{2}\right],[\mathrm{Zn}(\mathrm{OH}) \mathrm{L}]$ and $\left[\mathrm{Zn}(\mathrm{OH})_{2} \mathrm{~L}\right]^{-}$. The stability of the 1:1 zinc(II)-AHA species lies approximately halfway between that of the equivalent PYR and GLY complexes, 3.5-4 $\log \beta$ units below/above.

The zinc(II) stability constants of all functional groups show a strong ionic strength dependence in $\mathrm{NaCl}$. For PYR, GLY and AHA the 1:1 stability constant decrease by 1.67, 2.19, and $0.79 \log \beta$ units, respectively, between 0.00 and $1.00 \mathrm{M} \mathrm{NaCl}$. Since the absolute effect of ionic strength was of a similar order of magnitude, the relative effect is most significant in GLY which forms the weakest complexes with zinc(II). Whereas there was an almost $80 \%$ decrease in the 1:1 zinc(II)-GLY constant, the $1: 1 \mathrm{zinc}(\mathrm{II})$-PYR constant decreases by just $20 \%$. With respect to the validity of functional groups as representatives of real siderophores, the effect of $[\mathrm{NaCl}]$ on $\mathrm{DFOB}$ and AHA complexation is similar. The $1: 1 \mathrm{zinc}(\mathrm{II})$ stability constant for the siderophore decreases by $21 \%$ between 0.05 and $1.00 \mathrm{M} \mathrm{NaCl}$, whereas that of the functional group decreases by $14 \%^{30}$. The ionic strength dependence parameter $C$ shows no systematic change for any of the functional groups.

In Fig. 2a, intrinsic stability constants for the formation of zinc(II)-PYR species ([ZnL] and $\left.\left[\mathrm{ZnL}_{2}\right]^{2-}\right)$ at different ionic strengths calculated using the Davies equation are compared to the intrinsic stability constants for the same two species determined by fitting the modified version of the Extended Debye-Hückel equation to the full ionic strength dataset. Intrinsic stability constants for the full zinc(II)/PYR system calculated using the Davies equation are reported in Table S4. Figure 2b shows the fraction of complexed zinc(II) in a zinc(II)/ PYR system modelled at infinite dilution using intrinsic stability constants determined (i) directly, by fitting the modified version of the Extended Debye-Hückel equation to the full ionic strength stability constant dataset (ii-vi) indirectly, using the Davies equation to calculate activity coefficients and correct the PYR stability constants separately at $0.05,0.15,0.30,0.70$ and $1.00 \mathrm{M}$. The disagreement between the Davies- and modified Extended Debye-Hückel-based intrinsic speciation models increases as the Davies equation is applied to higher ionic strength thermodynamic data. At $\mathrm{pH} 5$, the $1.00 \mathrm{M}$ Davies-based intrinsic speciation model underpredicts the fraction of complexed zinc(II) by approximately $60 \%$ compared to the modified Extended Debye-Hückelbased intrinsic speciation model. At the same $\mathrm{pH}$, the 0.05 and $0.15 \mathrm{M}$ Davies-based intrinsic speciation models underpredict the fraction of complexed zinc(II) by approximately $20 \%$ and $40 \%$, respectively, compared to the modified Extended Debye-Hückel-based intrinsic speciation model. Firstly, this exercise clearly demonstrates the inconsistencies in speciation calculations that can arise when a geochemical model is parameterized using different sets of stability constants derived by applying the same indirect method (Davies equation) to different sets of ionic strength data, even when all the data is from the same study and within the activity model's supposed ionic strength range of applicability (for Davies equation $<0.5 \mathrm{M}$ i.e., $0.05,0.15$ and $0.3 \mathrm{M}$ ). Secondly, this exercise quantifies the improvement in the accuracy of geochemical speciation calculations that can be achieved by adopting a direct method for studying the ionic strength dependence of stability constants, rather than using an indirect method, as is the common practise.

To summarise, for the first time, we have developed an accurate description of the ionic strength dependence of zinc(II) stability constants with catecholate, $\alpha$-hydroxycarboxylate and hydroxamate functional groups in $\mathrm{NaCl}$. All functional groups showed a strong dependence on $[\mathrm{NaCl}]$. For PYR, GLY, and AHA, the 1:1 stability constant decreased by $1.67,2.19$ and $0.79 \log \beta$ units respectively between 0.00 and $1.00 \mathrm{M} \mathrm{NaCl}$. The overall effect of $[\mathrm{NaCl}]$ on DFOB, a hydroxamate siderophore, and AHA, a hydroxamate functional group, was similar. The 1:1 zinc(II) stability constant for the siderophore decreased by $21 \%$, whereas that of the functional group decreased by $14 \%$. We have quantified the benefits of the direct approach for studying the ionic strength dependence of stability constants; when the zinc(II)/PYR system is modelled at infinite dilution using high-precision intrinsic stability constants determined using a direct approach the accuracy of geochemical speciation calculations improves by at least $20 \%$ at $\mathrm{pH} 5$ compared to when the Davies equation is used instead to calculate intrinsic stability constants.

Comparing the susceptibility of different siderophore classes to salinity in terms of their zinc(II) chelating ability. The accurate descriptions for the ionic strength dependence of zinc(II) stability constants with siderophore functional groups developed above were subsequently employed to parameterize a two-component geochemical model (zinc(II) and ligand) for each ligand at multiple ionic strengths. Zinc(II) binding efficiency values were then calculated for specific $\mathrm{pH} / \mathrm{NaCl}$ conditions by normalizing the fraction of zinc(II) complexed by the ligand at any $\mathrm{pH} / \mathrm{NaCl}$ condition by the fraction of zinc(II) complexed by the ligand at the same $\mathrm{pH}$ in a freshwater solution (Eq. 2). Zinc(II) binding efficiency contour plots were produced for PYR, GLY and AHA between pH 5-9 and 0.01-1.00 M NaCl (Fig. 1g-i).

Changes in the concentration of $\mathrm{NaCl}$ have the most significant effect on the zinc(II) binding efficiency of GLY. For any $\mathrm{pH} / \mathrm{NaCl}$ condition, the zinc(II) binding efficiency of GLY is lower than the zinc(II) binding efficiency of PYR or AHA. For example, at pH 7 and $0.30 \mathrm{M} \mathrm{NaCl}$, the zinc(II) binding efficiency of GLY is 
(a)
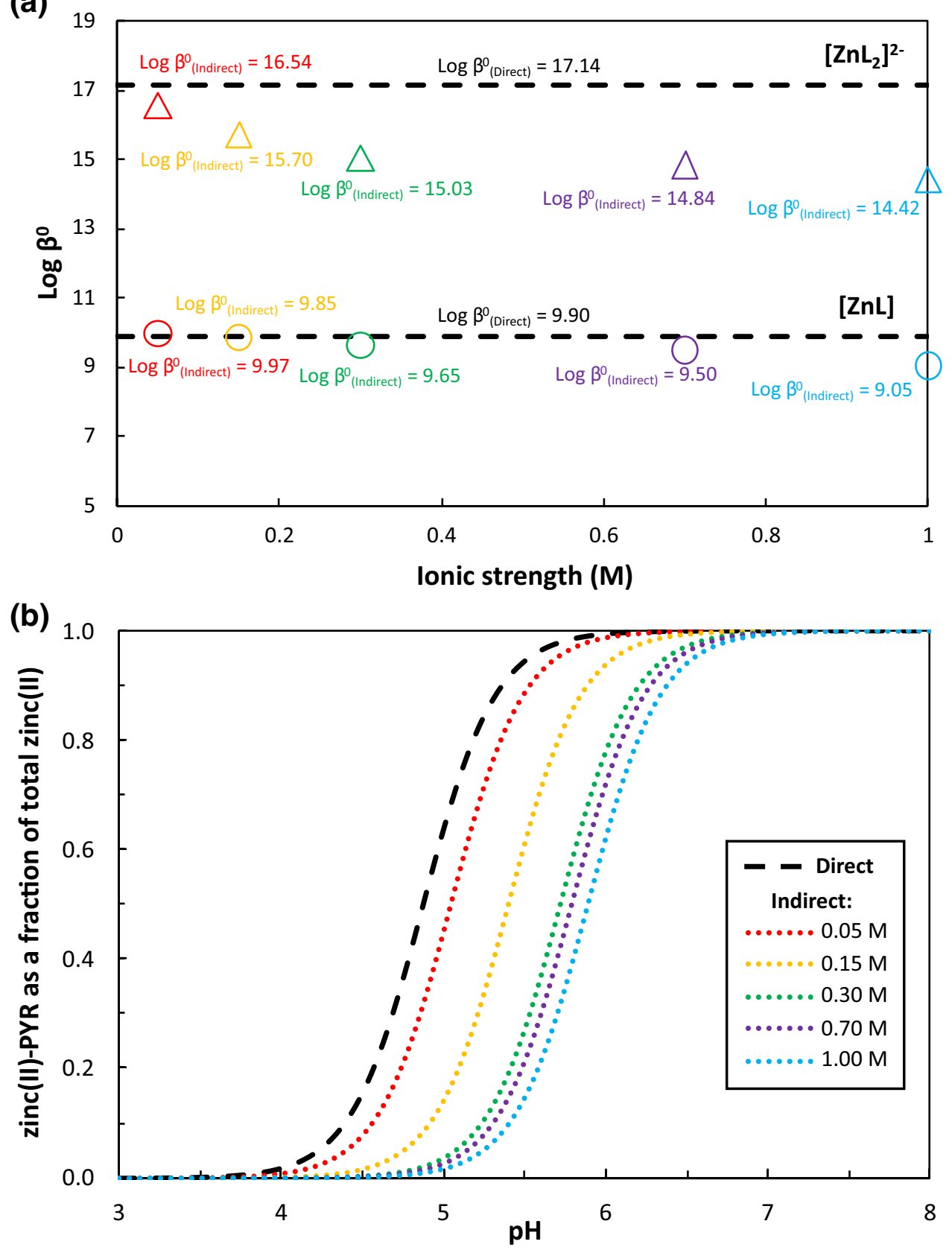

Figure 2. (a) Intrinsic stability constants for the formation of two zinc(II)-PYR (where PYR is pyrocatecholate) species ( $[\mathrm{ZnL}]$, shown as circles, and $\left[\mathrm{ZnL}_{2}\right]^{2-}$, shown as triangles) at different ionic strengths calculated indirectly using the Davies equation. The intrinsic stability constants for the same two species determined directly by fitting the modified version of the Extended Debye-Hückel equation to the full ionic strength dataset are shown as dashed lines. The error on the intrinsic stability constants is reported in Table S4. (b) Fraction of complexed zinc(II) in a $[\mathrm{Zn}]=10^{-6}$ and $[\mathrm{PYR}]=10^{-5}$ system modelled at infinite dilution using intrinsic stability constants determined (i) directly, by fitting the modified version of the Extended Debye-Hückel equation to the full ionic strength dataset; (ii-vi) indirectly, using the Davies equation to calculate activity coefficients and correct the zinc(II)-PYR stability constants at $0.05,0.15,0.30,0.70$ and $1.00 \mathrm{M}$ separately.

between 0.1 and 0.2 ; this implies that at $\mathrm{pH} 7$, a $0.30 \mathrm{M} \mathrm{NaCl}$ salinization of a freshwater solution causes the effectiveness of GLY for chelating zinc(II) to reduce by $80-90 \%$. At the same $\mathrm{pH} / \mathrm{NaCl}$ condition, the zinc(II) binding efficiencies of PYR and AHA are between 0.4-0.5 and 0.5-0.6, respectively. The 0.1 offset between the zinc(II) binding efficiency of PYR and AHA at $\mathrm{pH} 7$ and $0.30 \mathrm{M} \mathrm{NaCl}$ is consistent across the sampling region investigated. For example, at pH 8 and $0.70 \mathrm{M} \mathrm{NaCl}$ the zinc(II) binding efficiency of PYR and AHA are between $0.3-0.4$ and $0.4-0.5$, respectively. This suggests that under any given $\mathrm{pH}$ condition, the zinc(II) chelating ability 
of PYR is approximately $10 \%$ more susceptible to $\mathrm{NaCl}$ than $\mathrm{AHA}$. Hence, of the three functional groups, [ $\mathrm{NaCl}]$ has the least significant effect on the zinc(II) binding efficiency of AHA. For GLY, in 60\% of the sampling region investigated, zinc(II) binding efficiency was $<0.1$. For AHA, zinc(II) binding efficiency does not drop below 0.4 under any of the $\mathrm{pH} / \mathrm{NaCl}$ conditions studied.

The sensitivity of the zinc(II) binding efficiency of GLY to $\mathrm{NaCl}-$ demonstrated by a $60 \%$ reduction in zinc(II) binding capacity between pH $5-9$ at $0.10 \mathrm{M} \mathrm{NaCl}$-is similar to the effect of salinity on the zinc(II) binding capacity of humic acids previously observed ${ }^{22}$. The zinc(II) binding capacity of humic acid in river water decreased by $80-90 \%$ after a $0.02 \mathrm{M}$ increase in $\mathrm{NaCl}$; the relative zinc(II) binding capacity of humic acids remained between $10-15 \%$ across the rest of the salinity range investigated (up to approximately $0.35 \mathrm{M} \mathrm{NaCl}$ ) 22 . For PYR and AHA, the contour lines are horizontal at low $\mathrm{pH}$ and then begin to steepen as $\mathrm{pH}$ increases. Where contour lines are horizontal, the effect of $\mathrm{NaCl}$ on zinc(II) binding efficiency is independent of $\mathrm{pH}$. Where the contour lines steepen, this suggests that $\mathrm{pH}$ buffers the effect of $\mathrm{NaCl}$ on zinc(II) binding efficiency. At high $\mathrm{pH}, \mathrm{OH}^{-}$groups build-up in solution binding to $\mathrm{zinc}(\mathrm{II})$ ions, which in turn prevents the ligands under study coordinating to the metal ${ }^{61,62}$. The effect of $\mathrm{OH}^{-}$build-up on metal-ligand interactions is independent of $[\mathrm{NaCl}]$. Hence, it is not that $\mathrm{pH}$ is buffering the effect of $\mathrm{NaCl}$, rather, that competition between the ligands under study and the $\mathrm{OH}^{-}$groups is becoming increasingly important. GLY is a weak ligand and so competition with $\mathrm{OH}^{-}$for zinc(II) binding sites is already maximal at a low $\mathrm{pH}$. Thus, the effect of $\mathrm{NaCl}$ on the zinc(II) binding efficiency of GLY is independent of $\mathrm{pH}$ and the contour lines remain horizontal across the plot.

The hydrophobicity of a compound is represented by its partition coefficient (expressed as log P). A more negative value for $\log \mathrm{P}$ means the compound has a higher affinity for the aqueous phase. The $\log \mathrm{P}\left({ }_{c} \log \mathrm{P}\right)$ values for PYR, GLY and AHA (calculated using ChemDraw v18.2) are - 5.01, - 8.76 and - 0.54, respectively. Hence, the effect of $\mathrm{NaCl}$ on zinc(II) binding efficiency is greatest for the most hydrophilic ligand (GLY) and smallest for the most hydrophobic ligand (AHA). This observation fits with what has previously been proposed based on the quantification of the effect of hydrophobicity on the influence of ionic strength on protein-ligand binding affinity ${ }^{37}$.

To summarise, analysis of the effect of $[\mathrm{NaCl}]$ on the zinc(II) binding efficiency of the functional groups suggests that the order of increasing susceptibility of siderophore classes to salinity in terms of their zinc(II) chelating ability is: hydroxamate $<$ catecholate $<\alpha$-hydroxycarboxylate. This trend is consistent with the relative hydrophobicity of the ligands suggesting a link between the two observations. Since $\alpha$-hydroxycarboxylate ligands are associated with phytosiderophores, we predict that plant productivity is more sensitive to salinization than either bacterial or fungal productivity.

Assessing the importance of increased phytosiderophore release as a salinity tolerance mechanism for whole-plant zinc(II) status in barley. Finally, by applying the zinc(II) binding efficiency plot for the functional group relevant for phytosiderophores (GLY), we test the hypothesis that previously observed increases in phytosiderophore release by barley plants grown under salt stress in a medium without initial micronutrient deficiencies, are important for the salinity tolerance of whole-plant zinc(II) status.

The inset on Fig. 3 gives a schematic representation of the steps involved in phytosiderophore-assisted zinc(II) acquisition and highlights the particular aspect of the pathway we focus on to test our hypothesis: (step 1) phytosiderophores are exuded by root cells into the surrounding environment; (step 2) phytosiderophores form 1:1 water-soluble complexes with zinc(II), which may be in the soil solution, adsorbed to mineral and organic matter surfaces or present as hydroxide precipitates; and (step 3) the zinc(II)-phytosiderophore complexes passively diffuse back towards the root surface where the zinc(II) they have transported is assimilated into the plant ${ }^{13,63-65}$. Using the zinc(II) binding efficiency contour plot for GLY and Eq. (4), we can account for the effect of $\mathrm{NaCl}$ on the phytosiderophore-zinc(II) complexation step (step 2). This allows us to estimate how much phytosiderophore concentration, which is directly related to phytosiderophore release (step 1), must increase by at different salinities so that the overall amount of zinc(II) scavenged by the ligand and available to diffuse back towards the root-cell interface (step 3) is maintained at pre-salinization levels. We conduct our calculations at two $\mathrm{pH}$ conditions, representative for the $\mathrm{pH}$ range expected for real soil solutions ${ }^{46-48}$. Fig. 3 shows that after a $0.05 \mathrm{M}$ $\mathrm{NaCl}$ salinization of a soil solution, we would predict that a 1.8-times increase in phytosiderophore concentration is required to maintain the overall amount of zinc(II) scavenged by phytosiderophores. For phytosiderophores to scavenge the same amount of zinc(II) in a $0.30 \mathrm{M} \mathrm{NaCl}$ solution as in a freshwater solution, we estimate that phytosiderophore concentration would have to increase more than 7-times.

Previously reported experimental measurements with wild and cultivated barley plants grown in hydroponic solutions without initial micronutrient deficiencies, suggest there is a 2.5-3-times increase in phytosiderophore

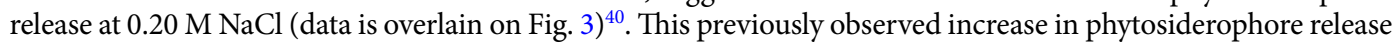
is of the same order of magnitude as the predicted increase in phytosiderophore concentration required under these conditions (calculated using the zinc(II) binding efficiency plot for GLY) to maintain the effectiveness of the uptake pathway (approximately 5-times). The calculations using the zinc(II) binding efficiency plot for GLY indicate that $\mathrm{pH}$ does not have a significant effect on the relative increase in phytosiderophore concentration required at different salinities; $<0.08$ and $>0.24 \mathrm{M} \mathrm{NaCl}$, there is no difference in the relative increase in phytosiderophores required at $\mathrm{pH} 5$ and $\mathrm{pH}$ 8. The largest difference in the calculated relative increase of phytosiderophore release required to maintain the effectiveness of the uptake pathway is at $0.16 \mathrm{M} \mathrm{NaCl} ; 3.8$ and 4-times increases at $\mathrm{pH} 5$ and 8 , respectively. The $\mathrm{R}_{x, y}$ curves steepen as ionic strength increases, at $\mathrm{pH} 5$ between 0.10 and $0.20 \mathrm{M} \mathrm{NaCl} \Delta \mathrm{R}_{x, y}=1.9$, whereas at $\mathrm{pH} 5$ between 0.20 and $0.30 \mathrm{M} \mathrm{NaCl} \Delta \mathrm{R}_{x, y}=2.8$. Siderophore production is an energetically demanding process ${ }^{6,67}$. Salt stress is likely to make phytosiderophore production and release more challenging ${ }^{68,69,70}$. Given this counterpoise-the exponentially increasing demand for phytosiderophores 


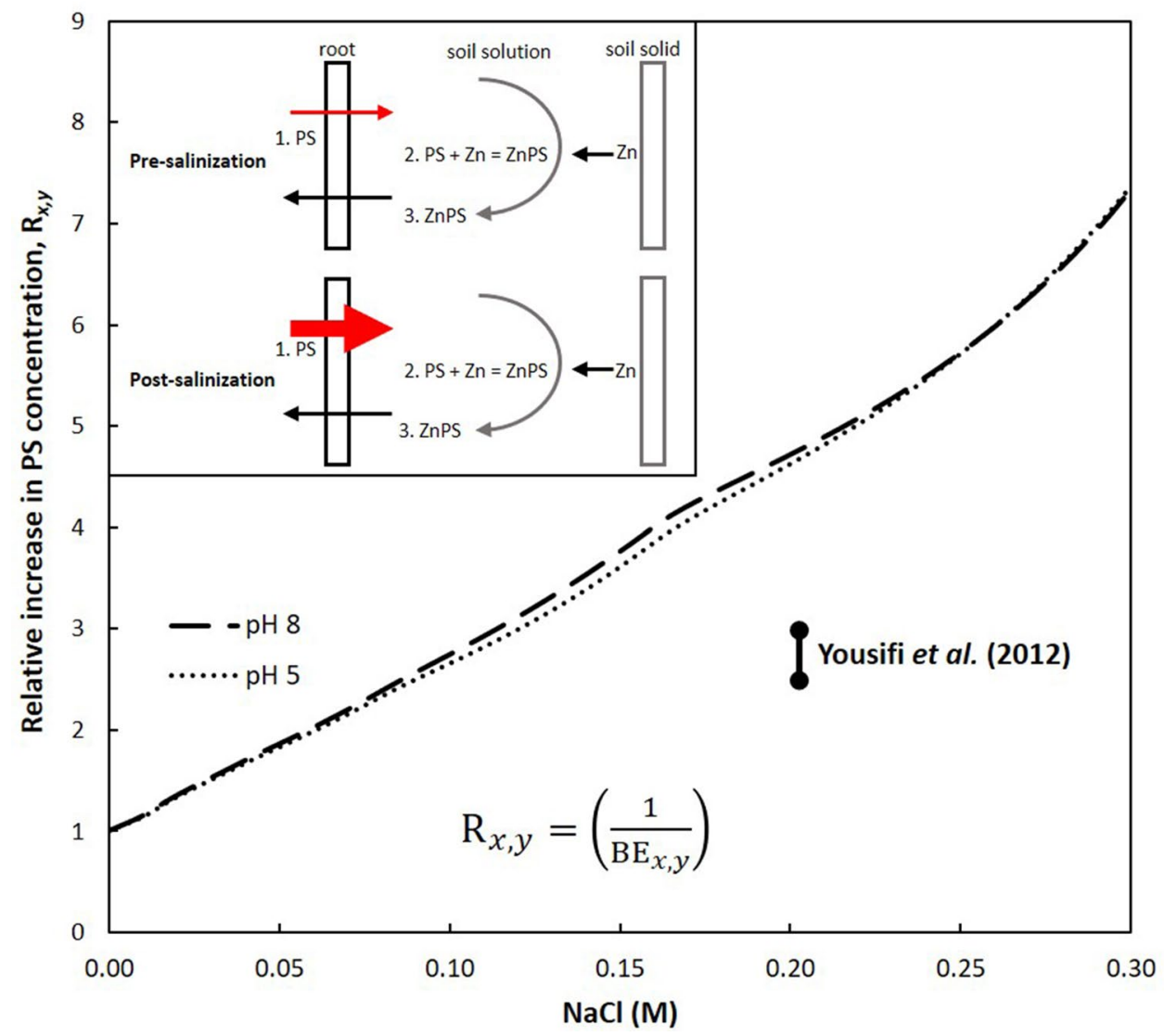

Figure 3. The inset gives a schematic representation of the steps involved in phytosiderophore-assisted zinc(II) acquisition and highlights the particular aspect of the pathway we focus on: (1) phytosiderophores (PS) are exuded by root cells into the surrounding environment; (2) phytosiderophores then form 1:1 water-soluble complexes with zinc(II), which may be in the soil solution, adsorbed to mineral and organic matter surfaces or present as hydroxide precipitates; and (3) the zinc(II)-phytosiderophore complexes passively diffuse back towards the root surface where the zinc(II) they have transported is assimilated into the plant. The main figure shows the calculated relative increase in phytosiderophore concentration required at different salinities for the overall amount of zinc(II) complexed by phytosiderophores to remain the same as in a freshwater solution. This is calculated using the equation displayed on the figure; where $\mathrm{BE}_{x, y}$ is the binding efficiency at $\mathrm{pH}=x$ and ionic strength $=y$ and $\mathrm{R}_{x, y}$ is the relative increase in the concentration of the ligand required at $\mathrm{pH}=x$ and ionic strength $=y$. Measurements with wild and cultivated barley plants grown in hydroponic solutions without initial micronutrient deficiencies (i.e., no micronutrient limitations prior to salinization), suggest there is a 2.5-3-times increase in phytosiderophore release after $0.20 \mathrm{M} \mathrm{NaCl}$ salinization of the growth medium (this data is overlain on the plot $)^{40}$.

as salinity increases $v s$. the increasing difficulty of synthesizing them-increased phytosiderophore release is most likely to be relevant for salinity tolerance at lower salinities.

To summarise, our calculation using the zinc(II) binding efficiency contour plot for GLY suggests that previously observed increases in phytosiderophore release by barley plants grown under salt stress in a medium without initial micronutrient deficiencies, are in line with the reduced zinc(II) binding efficiency of the a-hydroxycarboxylate ligand and hence important for the salinity tolerance of whole-plant zinc(II) status.

\section{Data availability}

The datasets generated during and/or analysed during the current study are available in the Zenodo repository, https://doi.org/10.5281/zenodo.4641710.

Received: 9 April 2021; Accepted: 23 July 2021

Published online: 18 August 2021

\section{References}

1. McLean, J. E., Pabst, M. W., Miller, C. D., Dimkpa, C. O. \& Anderson, A. J. Effect of complexing ligands on the surface adsorption, internalization, and bioresponse of copper and cadmium in a soil bacterium, Pseudomonas Putida. Chemosphere 91(3), 374-382. https://doi.org/10.1016/j.chemosphere.2012.11.071 (2013). 
2. Clemens, S. Metal ligands in micronutrient acquisition and homeostasis. Plant. Cell Environ. 42(10), 2902-2912. https://doi.org/ 10.1111 pce.13627 (2019).

3. Ma, H. et al. Elucidation of the mechanisms into effects of organic acids on soil fertility, cadmium speciation and ecotoxicity in contaminated soil. Chemosphere 239, 124706. https://doi.org/10.1016/j.chemosphere.2019.124706 (2020).

4. Ahmed, E. \& Holmström, S. J. M. Siderophores in environmental research: Roles and applications. Microb. Biotechnol. 7(3), 196-208. https://doi.org/10.1111/1751-7915.12117 (2014).

5. Butler, A. \& Theisen, R. M. Iron(III)-siderophore coordination chemistry: Reactivity of marine siderophores. Coord. Chem. Rev. 254(3-4), 288-296. https://doi.org/10.1016/j.ccr.2009.09.010 (2010).

6. Hider, R. C. \& Kong, X. Chemistry and biology of siderophores. Nat. Prod. Rep. 27(5), 637. https://doi.org/10.1039/b906679a (2010).

7. Kirby, M. E., Sonnenberg, J. L., Simperler, A. \& Weiss, D. J. Stability series for the complexation of six key siderophore functional groups with uranyl using density functional theory. J. Phys. Chem. A 124(12), 2460-2472. https://doi.org/10.1021/acs.jpca.9b106 49 (2020).

8. Harrington, J. et al. Structural dependence of Mn complexation by siderophores: Donor group dependence on complex stability and reactivity. GCA. 88, 106-119 (2012).

9. McRose, D. L., Seyedsayamdost, M. R. \& Morel, F. M. M. Multiple siderophores: Bug or feature?. JBIC J. Biol. Inorg. Chem. 23(7), 983-993. https://doi.org/10.1007/s00775-018-1617-x (2018).

10. Johnstone, T. C., Nolan, E. M. Beyond iron: Non-classical biological functions of bacterial siderophores. In Dalton Transactions. Royal Society of Chemistry April 14, 2015, pp 6320-6339. https://doi.org/10.1039/c4dt03559c.

11. Northover, G. H. R., Garcia-España, E. \& Weiss, D. J. Unravelling the modus operandi of phytosiderophores during zinc uptake in rice: The importance of geochemical gradients and accurate stability constants. J. Exp. Bot. https://doi.org/10.1093/jxb/eraa580 (2020).

12. Ghavami, N., Alikhani, H. A., Pourbabaee, A. A. \& Besharati, H. Study the effects of siderophore-producing bacteria on zinc and phosphorous nutrition of canola and maize plants. Commun. Soil Sci. Plant Anal. 47(12), 1517-1527. https://doi.org/10.1080/ 00103624.2016.1194991 (2016).

13. Weiss, D. et al. Isotope fractionation of zinc in the paddy rice soil-water environment and the role of 2'deoxymugineic acid (DMA) as zincophore under Zn limiting conditions. Chem. Geol. 577, 120271. https://doi.org/10.1016/j.chemgeo.2021.120271 (2021).

14. Suzuki, M. et al. Biosynthesis and secretion of mugineic acid family phytosiderophores in zinc-deficient barley. Plant J. 48(1), 85-97. https://doi.org/10.1111/j.1365-313X.2006.02853.x (2006).

15. Zaman, M. , Shahid, S. A., Heng, L., Shahid, S. A., Zaman, M., Heng, L. Soil salinity: Historical perspectives and a world overview of the problem. In Guideline for Salinity Assessment, Mitigation and Adaptation Using Nuclear and Related Techniques 43-53 (Springer, 2018). https://doi.org/10.1007/978-3-319-96190-3_2.

16. Alfarrah, N. \& Walraevens, K. Groundwater overexploitation and seawater intrusion in coastal areas of arid and semi-arid regions. Water 10(2), 143. https://doi.org/10.3390/w10020143 (2018).

17. Trenberth, K. Changes in precipitation with climate change. Clim. Res. 47(1), 123-138. https://doi.org/10.3354/cr00953 (2011).

18. Pendergrass, A. G., Knutti, R., Lehner, F., Deser, C. \& Sanderson, B. M. Precipitation variability increases in a warmer climate. Sci. Rep. 7(1), 1-9. https://doi.org/10.1038/s41598-017-17966-y (2017).

19. Errabii, T., Gandonou, C. H., Essalmani, H., Jamal; Senhaji, N. S. Effects of $\mathrm{NaCl}$ and mannitol induced stress on sugarcane (Saccharum Sp.) Callus Cultures. https://doi.org/10.1007/s11738-006-0006-1.

20. Saboora, A., Hajihashemi, S. \& Khatam, B. NaCl tolerance of wheat genotypes at germination and early seedling growth article in Pakistan. J. Biol. Sci. https://doi.org/10.3923/pjbs.2006.2009.2021 (2006).

21. Chand, M., Randhawa, N. S. \& Bhumbla, D. R. Effectiveness of zinc chelates in zinc nutrition of greenhouse rice crop in a salinesodic soil. Plant Soil 59(2), 217-225. https://doi.org/10.1007/BF02184195 (1981).

22. Lores, E. M. \& Pennock, J. R. The effect of salinity on binding of $\mathrm{Cd}, \mathrm{Cr}, \mathrm{Cu}$ and $\mathrm{Zn}$ to dissolved organic matter. Chemosphere 37(5), 861-874. https://doi.org/10.1016/S0045-6535(98)00090-3 (1998).

23. Cigala, R. M. et al. Zinc(II) complexes with hydroxocarboxylates and mixed metal species with Tin(II) in different salts aqueous solutions at different ionic strengths: Formation, stability, and weak interactions with supporting electrolytes. Monatshefte fur Chemie 146(4), 527-540. https://doi.org/10.1007/s00706-014-1394-3 (2015).

24. Laird, D. A., Koskinen, I. W. C. Triazine Soil Interactions. In The Triazine Herbicides 275-299 (Elsevier, 2008). https://doi.org/10. 1016/B978-044451167-6.50024-6.

25. Cigala, R. M. et al. Speciation of Tin(II) in aqueous solution: Thermodynamic and spectroscopic study of simple and mixed hydroxocarboxylate complexes. Monatshefte fur Chemie 144(6), 761-772. https://doi.org/10.1007/s00706-013-0961-3 (2013).

26. Daniele, P. G., Rigano, C. \& Sammartano, S. Ionic strength dependence of formation constants-I protonation constants of organic and inorganic acids. Talanta 30(2), 81-87. https://doi.org/10.1016/0039-9140(83)80023-X (1983).

27. Bretti, C., Foti, C. \& Sammartano, S. A new approach in the use of sit in determining the dependence on ionic strength of activity coefficients. Application to Some Chloride Salts Of Interest In The Speciation Of Natural Fluids. Chem. Speciat. Bioavailab. 16(3), 105-110. https://doi.org/10.3184/095422904782775036 (2004).

28. Bretti, C., De Stefano, C., Foti, C. \& Sammartano, S. Critical evaluation of protonation constants. Literature analysis and experimental potentiometric and calorimetric data for the thermodynamics of phthalate protonation in different ionic media. J. Solution Chem. 35(9), 1227-1244. https://doi.org/10.1007/s10953-006-9057-6 (2006).

29. Cigala, R. M. et al. Quantitative study on the interaction of $\mathrm{Sn}^{2+}$ and $\mathrm{Zn}^{2+}$ with some phosphate ligands, in aqueous solution at different ionic strengths. J. Mol. Liq. 165, 143-153. https://doi.org/10.1016/j.molliq.2011.11.002 (2012).

30. Northover, G. H. R., Mao, Y., Hanif M. D., Blasco, S., Vilar, R., Garcia-Espana, E. \& Weiss, D. J. The control of pH and ionic strength gradients on the interaction of low-molecular-weight organic acids and siderophores. ChemRxiv. Preprint (2021). https://doi.org/ 10.26434/chemrxiv.14706036.v1.

31. Domenico, P. A., Harris, D. R., Schwartz, F. W., Wiley, J., Chichester, N. Y., Brisbane, W. \& Singapore, T. Physical and Chemical Hydrogeology 2nd edn.

32. Pankow, J.; Taylor \& Francis Group. Aquatic Chemistry Concepts 2 nd edn.

33. Graziano, G. Role of salts on the strength of pairwise hydrophobic interaction. Chem. Phys. Lett. 483(1-3), 67-71. https://doi.org/ 10.1016/j.cplett.2009.10.040 (2009).

34. Mancera, R. L. Does salt increase the magnitude of the hydrophobic effect? A computer simulation study. Chem. Phys. Lett. 296(5-6), 459-465. https://doi.org/10.1016/S0009-2614(98)01080-X (1998).

35. Mancera, R. L. Computer simulation of the effect of salt on the hydrophobic effect. J. Chem. Soc. Faraday Trans. 94(24), 3549-3559. https://doi.org/10.1039/a806899b (1998).

36. Ghosh, T., Kalra, A. \& Garde, S. On the salt-induced stabilization of pair and many-body hydrophobic interactions. J. Phys. Chem. B 109(1), 642-651. https://doi.org/10.1021/jp0475638 (2005).

37. Papaneophytou, C. P., Grigoroudis, A. I., McInnes, C. \& Kontopidis, G. Quantification of the effects of ionic strength, viscosity, and hydrophobicity on protein-ligand binding affinity. ACS Med. Chem. Lett. 5(8), 931-936. https://doi.org/10.1021/ml500204e (2014). 
38. Ghafoor, K., AL-Juhaimi, F., Ozcan, M. M. \& Jahurul, M. H. A. Some nutritional characteristics and mineral contents in Barley (Hordeum Vulgare L.) seeds cultivated under salt stress. Qual. Assur. Saf. Crop. Foods 7(3), 363-368. https://doi.org/10.3920/QAS20 13.0380 (2015).

39. Akman, Z. Effects of plant growth regulators on nutrient content of young wheat and barley plants undersaline conditions. J. Anim. Vet. Adv. 8(10), 2018-2021 (2009).

40. Yousfi, S., Houmani, H., Zribi, F., Abdelly, C. \& Gharsalli, M. Physiological responses of wild and cultivated barley to the interactive effect of salinity and iron deficiency. (2012). https://doi.org/10.5402/2012/121983.

41. Alderighi, L. et al. Hyperquad simulation and speciation (HySS): A utility program for the investigation of equilibria involving soluble and partially soluble species. Coord. Chem. Rev. 184(1), 311-318. https://doi.org/10.1016/S0010-8545(98)00260-4 (1999).

42. Gans, P. \& O'Sullivan, B. GLEE: A new computer program for glass electrode calibration. Talanta 51(1), 33-37. https://doi.org/ 10.1016/s0039-9140(99)00245-3 (2000).

43. Gans, P., Sabatini, A. \& Vacca, A. Investigation of equilibria in solution. Determination of equilibrium constants with the HYPERQUAD suite of programs. Talanta 43(10), 1739-1753. https://doi.org/10.1016/0039-9140(96)01958-3 (1996).

44. Hu, W., Xie, J., Chau, H. W. \& Si, B. C. Evaluation of parameter uncertainties in nonlinear regression using Microsoft excel spreadsheet. Environ. Syst. Res. 4(1), 1-12. https://doi.org/10.1186/s40068-015-0031-4 (2015).

45. Harris, W. R., Raymond, K. N. \& Weitl, F. L. Ferric ion sequestering agents. 6. The spectrophotometric and potentiometric evaluation of sulfonated tricatecholate ligands. J. Am. Chem. Soc. 103(10), 2667-2675. https://doi.org/10.1021/ja00400a030 (1981).

46. Bravin, M. N., Tentscher, P., Rose, J. \& Hinsinger, P. Rhizosphere PH Gradient Controls Copper Availability in a Strongly Acidic Soil. Environ. Sci. Technol. 43(15), 5686-5691. https://doi.org/10.1021/es900055k (2009).

47. Gollany, H. T. \& Schumacher, T. E. Combined use of colorimetric and microelectrode methods for evaluating rhizosphere PH. Plant Soil 154(2), 151-159. https://doi.org/10.1007/BF00012520 (1993).

48. Kirk, G. J. D. Root ventilation, rhizosphere modification, and nutrient uptake by rice. In Systems Approaches for Agricultural Development 221-232 (Springer, Netherlands, 1993). https://doi.org/10.1007/978-94-011-2842-1_13.

49. Li, J. \& Heap, A. D. Spatial interpolation methods applied in the environmental sciences: A review. In Environmental Modelling and Software 173-189 (Elsevier, 2014). https://doi.org/10.1016/j.envsoft.2013.12.008.

50. Gergely, A., Kiss, T. \& Deák, G. Complexes of 3,4-dihydroxyphenyl derivatives. II. Complex formation processes in the Nickel(II)L-DOPA and Zinc(II)-L-DOPA systems. Inorganica Chim. Acta 36(1), 113-120. https://doi.org/10.1016/S0020-1693(00)89379-2 (1979).

51. Griesser, R. \& Sigel, H. Ternary complexes in solution. XI. complex formation between the cobalt(h)-, nickel(ii)-, copper(ii)-, and zinc(II)-2,2'-bipyridyl 1:1 complexes and ethylenediamine, glycinate, or pyrocatecholate. Inorg. Chem. 10(10), 2229-2232. https:// doi.org/10.1021/ic50104a028 (1971).

52. Das, A. K. Studies on mixed ligand complexes of cobalt(II), nickel(II), copper(II) and zinc(II) involving 8-hydroxyquinoline5-sulphonic acid as a primary ligand and substituted catechols as secondary ligands. Transition Met. Chem. 14, 200-209 (1989).

53. Das, A. K. Astatistical aspects of the stabilities of ternary complexes of cobalt(II), nickel(II), copper(II) and zinc(II) involving amino-polycarboxylic acids and heteroaromatic $\mathrm{N}$-bases as primary ligands and acetohydroxamic acid as a secondary ligand. Transition Met. Chem. 14, 66-68 (1989).

54. Cannan, R. K. \& Kibrick, A. Complex formation between carboxylic acids and divalent metal cations. J. Am. Chem. Soc. 60(10), 2314-2320. https://doi.org/10.1021/ja01277a012 (1938).

55. Farkas, E., Brown, D. A., Cittaro, R. \& Glass, W. K. Metal complexes of glutamic acid- $\gamma$-hydroxamic acid (Glu- $\gamma$-Ha) (N-hydroxyglutamine) in aqueous solution. J. Chem. Soc. Dalt. Trans. 18, 2803-2807. https://doi.org/10.1039/DT9930002803 (1993).

56. Farkas, E., Enyedy, É. A. \& Csóka, H. Some factors affecting metal ion-monohydroxamate interactions in aqueous solution. J. Inorg. Biochem. 79(1-4), 205-211. https://doi.org/10.1016/S0162-0134(99)00158-0 (2000).

57. Warnke, Z. Investigation on divalent metal complexes with oxyacids in aqueous solutions. 6. Potentiometric investigation on copper(II), zinc(II), and cadmium(II) complexes with glycolic acd. Rocz. Chem. 43, 1939 (1969).

58. Lengyel, T. Investigations on ion exchange equilibria with radioactive tracer method. 15. Liquid ion exchange technique for investigating mixed complex species of zinc with glycolic and alpha-hydroxyisobutyric acid. Acta Chim. Acad. Sci. Hung. 60, 373 (1969).

59. Athavale, V. T., Prabhu, L. H. \& Vartak, D. G. Solution stability constants of some metal complexes of derivatives of catechol. J. Inorg. Nucl. Chem. 28(5), 1237-1249. https://doi.org/10.1016/0022-1902(66)80450-5 (1966).

60. Portanova, R., Lajunen, L. H. J., Tolazzi, M. \& Piispanen, J. Critical evaluation of stability constants for $\alpha$-hydroxycarboxylic acid complexes with protons and metal ions and the accompanying enthalpy changes: Part II. Aliphatic 2-hydroxycarboxylic acids (IUPAC technical report). Pure Appl. Chem. 75(4), 495-540. https://doi.org/10.1351/pac200375040495 (2003).

61. Krężel, A. \& Maret, W. The biological inorganic chemistry of zinc ions. Arch. Biochem. Biophys. 611, 3-19. https://doi.org/10. 1016/j.abb.2016.04.010 (2016).

62. Al-Sogair, F. M.; Operschall, B. P.; Sigel, A.; Sigel, H.; Schnabl, J.; Sigel, R. K. O. Probing the Metal-Ion-Binding Strength of the Hydroxyl Group. In Chemical Reviews. American Chemical Society August 10, 964-5003 (2011). https://doi.org/10.1021/cr100 $415 \mathrm{~s}$.

63. Gries, D., Brunn, S., Crowley, D. E. \& Parker, D. R. Phytosiderophore release in relation to micronutrient metal deficiencies in Barley. Plant Soil 172(2), 299-308. https://doi.org/10.1007/BF00011332 (1995).

64. Welch, R. M. \& Shuman, L. Micronutrient nutrition of plants. CRC Crit. Rev. Plant Sci. 14(1), 49-82. https://doi.org/10.1080/07352 689509701922 (1995).

65. Arnold, T. et al. Evidence for the mechanisms of zinc uptake by rice using isotope fractionation. Plant. Cell Environ. 33(3), 370-381. https://doi.org/10.1111/j.1365-3040.2009.02085.x (2010).

66. Haas, H. Fungal siderophore metabolism with a focus on Aspergillus fumigatus. Nat. Prod. Rep. 31(10), 1266-1276. https://doi. org/10.1039/c4np00071d (2014).

67. Griffin, A. S., West, S. A. \& Buckling, A. Cooperation and competition in pathogenic bacteria. Nature 430(7003), 1024-1027. https://doi.org/10.1038/nature02744 (2004).

68. Wu, D. et al. Tissue metabolic responses to salt stress in wild and cultivated barley. PLoS ONE 8(1), e55431. https://doi.org/10. 1371/journal.pone.0055431 (2013).

69. Widodo, Patterson, J. H.; Newbigin, E. et al.. Metabolic responses to salt stress of Barley (Hordeum Vulgare L.) cultivars, sahara and clipper, which differ in salinity tolerance. J. Exp. Bot. 60(14), 4089-4103 (2009). https://doi.org/10.1093/jxb/erp243

70. Yang, C.-W. et al. Comparative effects of salt-stress and alkali-stress on the growth, photosynthesis, solute accumulation, and ion balance of Barley plants. Phytosynthetica 47, 79-86 (2009).

\section{Acknowledgements}

G.H.R.N. is a recipient of an Engineering and Physical Sciences Research Council studentship (EP/R512540/1). Y.M. is a recipient of an Analytical Chemistry Trust Fund summer studentship award. D.J.W. acknowledges the financial support of the William Jr Kenan Foundation at Princeton University. 


\section{Author contributions}

The experimental data was collected and analysed by G.H.R.N., Y.M., S.B., and E.G.E. Modelling was conducted by G.H.R.N., H.A., R.V. and D.J.W. The manuscript was written by GHRN after discussions with all authors.

\section{Competing interests}

The authors declare no competing interests.

\section{Additional information}

Supplementary Information The online version contains supplementary material available at https://doi.org/ 10.1038/s41598-021-95736-7.

Correspondence and requests for materials should be addressed to G.H.R.N. or D.J.W.

Reprints and permissions information is available at www.nature.com/reprints.

Publisher's note Springer Nature remains neutral with regard to jurisdictional claims in published maps and institutional affiliations.

(c) (i) Open Access This article is licensed under a Creative Commons Attribution 4.0 International License, which permits use, sharing, adaptation, distribution and reproduction in any medium or format, as long as you give appropriate credit to the original author(s) and the source, provide a link to the Creative Commons licence, and indicate if changes were made. The images or other third party material in this article are included in the article's Creative Commons licence, unless indicated otherwise in a credit line to the material. If material is not included in the article's Creative Commons licence and your intended use is not permitted by statutory regulation or exceeds the permitted use, you will need to obtain permission directly from the copyright holder. To view a copy of this licence, visit http://creativecommons.org/licenses/by/4.0/.

(C) The Author(s) 2021 